\title{
BIOEMEDICAL CONSIDERATION IN THE MANUFACTURE, CLINICAL TRAIL AND BIOEQUIVALENCE STUDIES OF PHARMACEUTICALS
}

\author{
A B M Faroque \\ Professor and Dean, \\ Faculty of Pharmacy, University of Dhaka, Bangladesh.
}

\begin{abstract}
Bangladesh pharmaceutical sector has been growing at a remarkable speed since 1982. From the meager $30 \%$ national market share, now it is supplying $97 \%$ of our annual demand. Around 1,100 generics are now available in a total of around 12,000 trade name products. The national market size has crossed 6,000 crore taka per annum, where the local multinational share is only $7 \%$. Our industries are now exporting drugs to 72 countries. But just because our pharmaceutical sector has developed its own backbone does not meant that our pharmaceutical industries have solved the relevant bioethical questions. There are complaints that some companies do not pursue necessary bioethical norm as at various levels of its manufacturing processes. Still a good number of small companies sell sub-standard and counterfeit drugs, and yet some are not following accepted GMP standards. Moreover, for capturing foreign markets we need clinical trials and bioequivalence study results. These study needs human subjects as volunteers. In a poverty-stricken country like us, if we do not establish these clinical trial and bioequivalence norms, everything becomes irrelevant. If we can establish theses norms, this could be the beginning of a new era for further growth of our pharmaceutical industries vis-à-vis our public health national economy.
\end{abstract}

INTRODUCTION: Bangladesh has a severely war-torn economy, seriously disrupted infrastructure and a huge deficit in foreign currency when it earned independence in 1971. All these factors aggravated the overall health care situation of the country. At that time, country's health care facilities, including the supply of medicines, were mostly depending on import. At that time more than $80 \%$ drugs of our annual demand were being imported. In 1982, a National Drug Policy was announced that largely encouraged local production in our pharmaceutical sector. Under the umbrella of this drug policy, a large number of local companies invested in creating local pharmaceutical manufacturing facilities. This trend still continues. The present government is also encouraging these local investors and our hon'ble 
Prime Minister Her Excellency Sheikh Hasina has also declared her policy to restrict import of drugs that are locally manufactured. This market protection stimulated the growth of our national pharmaceutical companies and has led to a national aspiration towards selfsufficiency in pharmaceutical sectors.

PHARMACEUTICAL SECTOR OF BANGLADESH: In today's Bangladesh, the pharmaceutical sector has emerged as one of the fastest growing business sector, its current annual market size is about 6,000 crore taka, it is the second highest contributors to our national exchequer, and it is the largest white collar labor intensive employment sector. In 1982, market share of the multinational pharmaceutical companies was $75 \%$, only $25 \%$ was contributed by our national companies. But today our pharmaceutical market is dominated by local manufacturers and the top 10 pharmaceutical companies are mostly local companies. Today we are moving towards self-sufficiency in medicine by getting $97 \%$ our drugs that are consumed annually from local manufacturers and only $3 \%$ from import. These very meager imported items are vaccines, anticancer drugs, insulin etc. Whereas, drug import figures for Singapore is $75 \%$, Myanmar $90 \%$ and Shri Lanka $85 \%$.

Another very import point regarding our pharmaceutical industries is that our pharma companies are heading towards self-sufficiency without compromising the quality. Bangladesh is now capable of producing high quality pharmaceutical products. This was possible because our industry now uses state-of-the-art manufacturing technology, very sophisticated QC equipment and apparatus, and highly skilled human resource. A good number of these plants have achieved MHRA, EU, GCC, TGA and ANVISA certifications. Now some of them are improving themselves further and trying to obtain the FDA certification too. Moreover, our pharmaceutical industries are achieving self-sufficiency without affecting the consumers' affordability. Before Drug Policy in 1982, price of one Amoxicillin capsule was Tk. 7, now it is Tk. 3.60; Doxycycline capsule was Tk. 3.95, now it is Tk. 2 ; and Diclofenac tablet was Tk. 9, now it is Tk 0.50 only.

In this way another national aspiration has developed in our pharmaceutical sector i.e. turning an import-based pharmaceutical industry into an exporter of quality medicines. Today, Bangladesh is successfully exporting its quality products to 87 countries in Asia, Africa, Latin America and Europe. The drugs we are exporting are a wide range of pharmaceutical products covering all major therapeutic classes and doses forms. Besides 
conventional products we are exporting high-tech specialized products like inhalers, nasal spray, infusions etc. The quality and efficacy of the products being exported from Bangladesh have been highly appreciated in all the countries we are exporting. Bangladesh now has become one of the cheapest sources of quality medicines in the world. So the generic pharmaceutical market of the world is now open for Bangladesh.

BIOETHICS: But just because our pharmaceutical sector has developed its own backbone does not mean that all our pharmaceutical industries have solved the relevant bioethical questions. Though we are proud of many of our pharmaceutical companies; still there are complaints that some other companies do not pursue necessary bioethical norms at various levels of their manufacturing processes. Still a good number of companies sell sub-standard and counterfeit drugs, and yet some are not following the accepted GMP standards. This is very much unfortunate and need to be addressed properly both for the sake of public health and for the interest of the pharmaceutical companies.

The deviations that some companies of our country are showing in general are : not employing enough qualified pharmacists, absence of regular health check-up of the personnel directly in contact with the manufacturing process, not having formal GMP training for all personnel of vital departments, not following proper in-process quality control measures, not having proper QC instruments, not using appropriate reference standards, not having any authorized vendor list for procurement of raw materials, not performing $100 \%$ sampling for identification of APIs and excipients, not having standard cleaning schedules for production machineries and surroundings, not rotating the disinfectants for cleaning of floors, not validating the production equipment and processes properly, not having acceptable waste disposal system etc. These variations are neither acceptable nor good for developing a positive image of our overall pharmaceutical manufacturers. Ethical selfregulation could be a means to minimize such deviations. Though these companies are not competing in the export market but their products are being sold in the local market. This is an important concern for us because these companies are not GMP-compliant. Fortunately market share of these companies is negligible.

If we consider exporting our medicine to the world market, it needs clinical trial and bioequivalence studies. As clinical trials and bioequivalence studies are experiments on human subjects, this means that ethical issues are always to be considered. These 
experimental subjects are assigned either to receive the experimental intervention, or to receive an already established treatment product. WHO's approach to bring all clinical trial data including trial conducted by private pharmaceutical companies, into a clinical trial registry is an excellent idea. Poor counties like Bangladesh will be benefited from this approach because we have a very large poor population that might be used as guinea pigs if appropriate national bioethical principles are not there. Right to informed consent and getting unbiased scientific health information about any experimental product is most important. It is an issue if global justice too.

CONCLUSION: In a poverty stricken country like Bangladesh, if we do not establish these clinical trial and bioequivalence study norms nationally, everything else becomes irrelevant. Growth of our national pharmaceutical industry or earning a huge foreign currency without bioethical considerations is absolutely impossible and unacceptable. If we can establish these national bioethical norms, this could be the beginning of a new era for future growth of our pharmaceutical industries vis-á-vis our public health and national economy.

We want to keep it in mind that ethical behavior is essential if a business is to function effectively. Policing through self-regulation is a good idea where bioethics can play a vital role. We need proper national ethical guidelines and this ultimately will be a right step in the right direction for further advance of our pharmaceutical industries, for better health care coverage of our poor people and for a potentially remarkable growth of our national economy. 